\title{
Macroglossia: An Uncommon Manifestation of Primary Hypothyroidism due to Hashimoto's Thyroiditis in a Teenage Child
}

\author{
Manish Gutch, ${ }^{1}$ Bhattacharjee Annesh, ${ }^{1}$ Kumar Sukriti, ${ }^{2}$ Gupta Arpit, ${ }^{1}$ Singh Somendra Rao ${ }^{1}$ \\ ${ }^{1}$ Department of Medicine, King George's Medical College, Lucknow, Uttar Pradesh, India \\ ${ }^{2}$ Department of Radiodiagnosis, King George's Medical College, Lucknow, Uttar Pradesh, India
}

\begin{abstract}
Thyroid disorders are prevalent in the paediatric population and untreated hypothyroidism leads to several adverse consequences like mental retardation, neurological impairment, short stature, delayed puberty and increased morbidity. Owing to a wide range of non-specific clinical manifestations, one must have a high index of suspicion for timely diagnosis and treatment of primary hypothyroidism. We describe the case of an adolescent girl who presented with short stature, delayed puberty and feeding difficulties owing to undiagnosed and subsequently untreated hypothyroidism.
\end{abstract}

Key words: macroglossia, short stature, delayed puberty, hypothyroidism

\section{INTRODUCTION}

Primary hypothyroidism is a common paediatric entity which is frequently undiagnosed and untreated. Its protean manifestations include lethargy, hypothermia, hypotonia, constipation and mental retardation. ${ }^{1}$ Oral manifestations causing difficulty in feeding include largesized tongue (macroglossia), delayed dentition and crowding of teeth. ${ }^{2}$ Long term consequences include growth retardationand pubertal delay, though isosexual precocious puberty may occur in rare cases. ${ }^{3-8}$

Here we describe a 16-year-old adolescent girl presenting with short stature, delayed puberty and feeding difficulties due to undiagnosed and subsequently untreated hypothyroidism.

\section{CASE}

A 16-year-old Indian girl presented to the endocrinology out-patient department with short stature and delayed pubertal development with absence of menarche. She also complained of gradually progressive difficulty in chewing food since last 2 years. There was no history suggestive of dental malocclusion, trauma or any abnormalities in jaw opening or closing. There was no family history of growth retardation or pubertal delay, neither any surgical intervention nor radiation exposure during childhood. She was born of an uneventful pregnancy at 36 weeks gestation age by normal spontaneous vaginal delivery with normal birth length and weight. There was no history of any chronic illness during childhood. She studied in $8^{\text {th }}$ grade and her academic performance was average.

eISSN 2308-118x

Printed in the Philippines

Copyright (C) 2017 by the JAFES

Received: July 19, 2016. Accepted: November 4, 2016.

https://doi.org/10.15605/jafes.032.01.08
On examination, facial puffiness was prominent along with a dry and scaly skin. There was crowding of her incisors (Figure 1). She had a large sized tongue, more evident on protrusion (Figure 2). Her hair seemed brittle with mild alopecia noted in the frontal region. There was no madarosis of eyebrows. There were no signs of goitre while the higher mental functions and neurological examination were within normal limits with slightly sluggish deep tendon reflexes in the lower limbs (grade $1+)$. Anthropometric measurements revealed a standing height of $134 \mathrm{~cm}\left(<3^{\text {rd }}\right.$ percentile for age and sex $)$ and an arm span of $132 \mathrm{~cm}$. She weighed $28 \mathrm{~kg}\left(<3^{\text {rd }}\right.$ percentile for age and sex). The mid-parental height as calculated from her parents was $164 \mathrm{~cm}$. Tanner scoring was B1, P1 and A1.

Her investigations revealed the following (Table 1): Hemoglobin=10.2 g/dl, and general blood picture suggestive of normocytic normochromic anemia, normal serum electrolytes, CPK and LDH. Liver functions and kidney functions were within normal limits. Thyroid function tests revealed TSH level $>150 \mu \mathrm{IU} / \mathrm{L}$ (normal: 0.4-5) with low T4 and T3 levels, suggestive of overt hypothyroidism. Anti-thyroid peroxidase antibody (Anti TPO Ab) was $>1000 \mathrm{IU} / \mathrm{ml}$ (normal: 0-50 IU/ml). Ultrasound study of the thyroid gland was mostly normal with a few hypoechoic lesions noted. Her bone age from x-ray of the left hand as calculated by Tanner-Whitehouse 2 was 8.9 years. Her gonadotropin levels (both FSH and LH) were low, implying pre-pubertal status. Thus, her short stature, delayed bone age and delayed pubertal development were attributed to hypothyroidism due to Hashimoto's thyroiditis. 


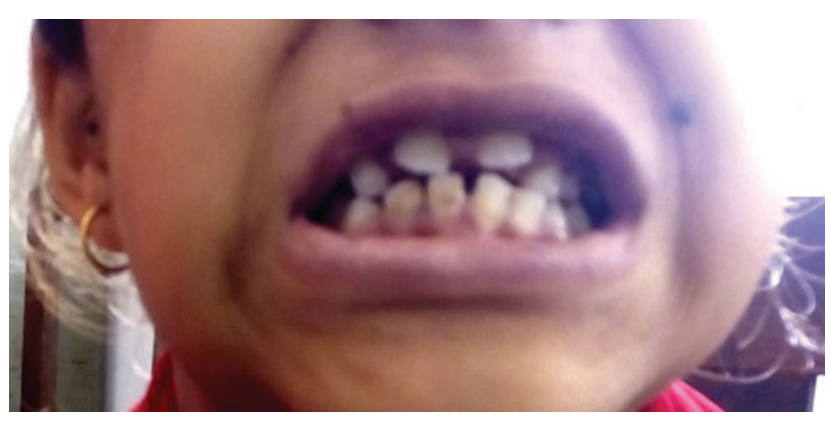

Figure 1. Dental anomalies due to large tongue.

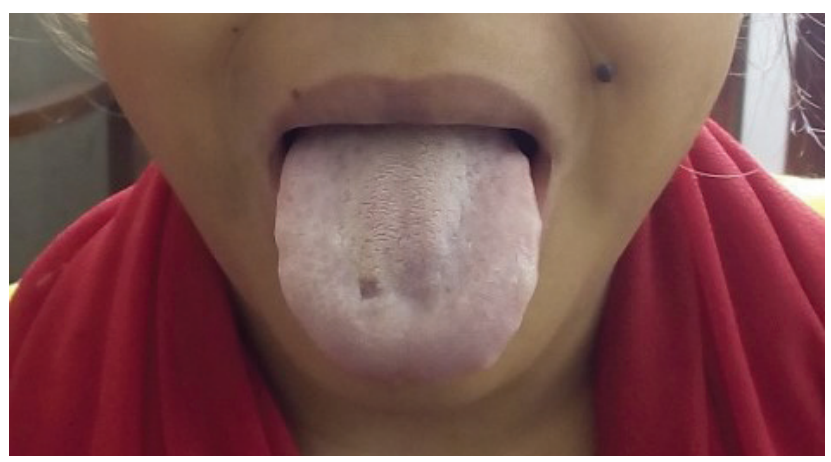

Figure 2. Macroglossia.

\begin{tabular}{ll}
\multicolumn{2}{l}{ Table 1. Laboratory investigations } \\
\hline Parameter & Lab Values \\
\hline Hemoglobin (Hb) & $10.2 \mathrm{~g} / \mathrm{dl}$ \\
Total Leuco. Count (TLC) & $5200 / \mathrm{cu} \mathrm{mm}$ \\
MCV & $75 \mathrm{fl}$ \\
Creatinine & $08 \mathrm{mg} / \mathrm{dl}$ \\
Sodium (Na) & $138 \mathrm{meg} / \mathrm{l}$ \\
Potassium (K) & $3.8 \mathrm{meq} / \mathrm{l}$ \\
Calcium(Ca)-total & $9.5 \mathrm{mg} / \mathrm{dl}$ \\
Creatinine Kinase (CK) & $50 \mathrm{U} / \mathrm{L}$ \\
LDH & $105 \mathrm{U} / \mathrm{L}$ \\
TSH & $>150 \mu \mathrm{\mu lU} / \mathrm{L}$ \\
T3 & $30 \mathrm{ng} / \mathrm{dl}$ \\
T4 & $2.5 \mu \mathrm{gg} / \mathrm{dl}$ \\
Anti-TPO antibody & $>1000 \mathrm{IU} / \mathrm{ml}$ \\
FSH & $0.7 \mathrm{IU} / \mathrm{L}$ \\
LH & $1.2 \mathrm{IU} / \mathrm{L}$ \\
\hline
\end{tabular}

She was started on levothyroxine replacement and counselled appropriately. After 6 months of therapy, she noted improvement in her chewing abilities. She is being monitored regularly for catch up growth and subsequent pubertal development.

\section{DISCUSSION}

Thyroid disorders are a fairly common occurrence in the paediatric population, and the prevalence of juvenile hypothyroidism was found to be $9.3-10.5 \%$ in the developing world. $^{9}$ The presentation ranges from asymptomatic, isolated biochemical abnormalities of thyroid function tests to overt clinical manifestations. Autoimmune thyroid disease, thyroid dysgenesis, binding protein abnormalities, TSH receptor mutations, thyroid hormone resistance, iodine deficiency, infectious thyroiditis are the common thyroid disorders observed in this age group. ${ }^{1}$
Overall, Hashimoto's Autoimmune Thyroiditis is the most common cause of hypothyroidism in iodine-sufficient areas of the world. The worldwide incidence is estimated to be $0.3-1.5$ cases per 1000 individuals with a definite gender predilection for females ( $\mathrm{M}: \mathrm{F}=15: 1)$.

Deficiency of thyroid hormones during intra-uterine life leads to impairment of normal fetal brain development. ${ }^{1}$ In childhood, hypothyroidism manifests as prolonged jaundice, umbilical hernia, constipation, lethargy, hypothermia and cold or mottled skin. Feeding difficulties are seen due to various oral manifestations like delayed eruption of teeth, malocclusion, large sized tongue (macroglossia) and thick lips. ${ }^{2}$ Macroglossia can be attributed to accumulation of glycosaminoglycans and over-development of tongue musculature. ${ }^{10}$

Hypothyroid children may present with short stature and delayed onset of puberty. Height deficit correlates with duration of untreated hypothyroidism and can be estimated by calculating the difference between chronological and bone age. ${ }^{3}$ They generally have very low T4 values and highly elevated TSH. On treatment with levothyroxine, bone age advances faster in comparison to height gain, hence final height always remains short of the genetic growth potential.

Besides, thyroid hormone deficiency results in delay of onset or retardation of progress of puberty, since it interferes with gonadotropin secretion. ${ }^{4}$ Treatment with levothyroxine normalises the gonadotropin secretion and allows further progress of puberty. In rare cases, long standing untreated hypothyroidism may result in paradoxical isosexual precocious puberty (Van-Wyk Grumbach Syndrome) due to action of high levels of TSH on the FSH receptors. ${ }^{5}$

Our patient had features of macroglossia, short stature and delayed puberty owing to long duration of undetected and untreated hypothyroidism. Hence, clinicians must be aware of the protean manifestations of primary hypothyroidism and treat the child timely to prevent long term adverse consequences.

\section{CONCLUSION}

Primary hypothyroidism must be diagnosed and treated early to provide opportunity for adequate gain in height and timely onset and progress of puberty before complete skeletal maturation occurs.

\section{Ethical Consideration}

Informed consent has been taken before submission of the manuscript.

\section{Statement of Authorship}

All authors certified fulfillment of ICMJE authorship criteria.

\section{Author Disclosure}

The authors have declared no conflict of interest. 


\section{Funding Source}

None.

\section{References}

1. Morreale de Escobar G.The role of thyroid hormone in fetal neurodevelopment. J Pediatr Endocrinol Metab. 2001;14(6):1453-62. PMID:11837499.

2. Chandna S, Bathla M. Oral manifestations of thyroid disorders and its management. Indian J Endocrinol Metab. 2011;15(6):S113-6. https://doi.org/10.4103/2230-8210.83343.

3. Rivkees SA, Bode HH, Crawford JD. Long-term growth in juvenile acquired hypothyroidism: The failure to achieve normal adult stature. N Engl J Med. 1998;318:599-602. https://doi.org/10.1056/ NEJM198803103181003.

4. $\quad$ Rosen DS, Foster C. Delayed puberty. Pediatr Rev.2001;22(9):309-15. https://doi.org/10.1542/pir.22-9-309.

5. Philip R, Saran S, Gutch M, Gupta KK. An unusual case of precocious puberty and macroorchidism. Thyroid Res Pract. 2013;10(1):29-31. https://doi.org/10.4103/0973-0354.105845.
6. Gutch M, Philip R, Philip R, Toms A, Saran S, Gupta KK. Skeletal manifestations of juvenile hypothyroidism and the impact of treatment on skeletal system. Indian J Endocrinol Metab. 2013; 17(7):181-3.https://doi.org/10.4103/2230-8210.119565.

7. Gutch M, Kumar S, Gupta KK, Syed RM, Gupta A, Bhattacharjee A, et al. Aetiology of short stature in northern India. J ASEAN Fed Endocr Soc. 2016;31(1):23.https://doi.org/10.15605/jafes.031.01.05.

8. Kumar S, Gutch M, Syed RM, Gupta AK, Gupta KK, Arya TVS. Prevalence and clinical profile of celiac disease in patients with type 1 diabetes mellitus in Western Uttar Pradesh, India. J ASEAN Fed Endocr Soc. 2015;30(2):142-6.https://doi.org/10.15605/jafes.030.02.02.

9. Gutch M, Kumar S, Razi SM, Gupta A, Kumar S, Gupta KK, Singh MM. Prevalence of short stature in juvenile hypothyroidism and the impact of treatment on various skeletal manifestation and growth velocity in a teritary care center. CHRISMED J Health Res. 2015;2(3):251-6. https://doi.org/10.4103/2348-3334.158704.

10. Rodríguez MER, García MAM, Flores IS. Congenital hypothyroidism and its oral manifestations. Revista Odontológica Mexicana. 2014;18(2):133-8. http://www.medigraphic.com/pdfs/odon/uo-2014/ uoi142i.pdf.

Authors are required to accomplish, sign and submit scanned copies of the JAFES Author Form consisting of: (1) Authorship Certification, that all the requirements for authorship have been met by each author, and that the final version of the manuscript has been read and approved by all authors; (2) the Author Declaration, that the article represents original material that is not being considered for publication or has not been published or accepted for publication elsewhere; (3) the Statement of Copyright Transfer laccepted manuscripts become the permanent property of the JAFES and are licensed with an Attribution-Share Alike-Non-Commercial Creative Commons License. Articles may be shared and adapted for non-commercial purposes as long as they are properly cited]; and the ICMJE form for Disclosure of Potential Conflicts of Interest. For original articles, authors are required to submit a scanned copy of the Ethics Review Approval of their research as well as registration in trial registries as appropriate. For manuscripts reporting data from studies involving animals, authors are required to submit a scanned copy of the Institutional Animal Care and Use Committee approval. For Case Reports or Series, and Images in Endocrinology, consent forms, are required for the publication of information about patients; otherwise, authors declared that all means have been exhausted for securing such consent. Articles and any other material published in the JAFES represent the work of the author(s) and should not be construed to reflect the opinions of the Editors or the Publisher. 